\title{
Inhibition of Intestinal Epithelial DNA Synthesis and Adaptive Hyperplasia after Jejunectomy in the Rat by Suppression of Polyamine Biosynthesis
}

\author{
Gordon D. Luk and Stephen B. Baylin \\ Oncology Center and Department of Medicine, \\ The Johns Hopkins University School of Medicine, \\ Baltimore, Maryland 21205
}

bstract. Transient increases in the activity of ornithine decarboxylase (ODC), the first and ratelimiting enzyme in polyamine biosynthesis, may be critical to initiation of cell growth. We previously reported such increases in ODC activity, and the polyamines, putrescine, and spermidine in rat ileal mucosa between days 1 and 4 after intestinal resection. During this time, there is initiation of mucosal cell hyperplasia, as measured morphologically and biochemically. Intestinal weight and mucosal thickness increase, as do mucosal DNA content and DNA synthesis. In the present study, we gave rats the specific irreversible ODC inhibitor, $\alpha$-difluoromethyl ornithine (DFMO), beginning $3 \mathrm{~d}$ before jejunectomy. DFMO completely suppressed the increases in ODC activity and polyamine content in the intestinal mucosa. The suppression in ODC activity was associated with an $87 \%$ suppression of DNA synthesis, and resulted in a complete abolition of intestinal adaptation, as manifested by the absence of intestinal weight gain, increase in mucosal thickness, or increase in crypt cell production. Our results indicate that the increases in ODC activity and polyamine biosynthesis are critical for adaptive postresectional crypt cell proliferation in vivo, and that the critical step mediated by polyamines in this adaptive process is the onset of new DNA synthesis.

Dr. Luk was supported by a Clinical Investigator Award (AM00774) from the National Institute of Arthritis, Diabetes, Digestive and Kidney Diseases, and by an American Gastroenterological Association/Robins Research Scholar Award.

Received for publication 11 January 1984 and in revised form 17 April 1984.

J. Clin. Invest.

(c) The American Society for Clinical Investigation, Inc.

0021-9738/84/09/0698/07 \$1.00

Volume 74, September 1984, 698-704

\section{Introduction}

The products of the polyamine biosynthetic pathway, putrescine, spermidine, and spermine, have been found in all nucleated prokaryotic and eukaryotic cell types studied. The first and rate-limiting step in polyamine biosynthesis is the decarboxylation of the precursor, ornithine, by ornithine decarboxylase (ODC, ${ }^{1}$ EC 4.1.1.17). The activity of ODC is low in quiescent cells, but increases markedly during the initial stages of cell proliferation and differentiation (1-6). This increase in $O D C$ is often one of the earliest events during the transition from quiescence to proliferation, and is associated with the rapid accumulation of cellular polyamines (5-8).

In recent investigations, we have examined polyamine biosynthesis in the rapidly proliferating intestinal epithelium (mucosa), because this cell system offers an excellent model for the study of the potential role of ODC and polyamine biosynthesis in cell proliferation in the intact animal. We have recently shown that ODC activity increases during the early stages of intestinal adaptation after jejunectomy and during lactation $(9,10)$. After jejunectomy (resection of the proximal $50 \%$ of the small intestine) in the rat, morphological and functional adaptation occur in the intestinal remnant-the ileum. This adaptation is achieved by mucosal hyperplasia, which leads to increased villus height and crypt depth, as well as dilation and lengthening of the ileum (11-14). We have recently shown that this morphologic and biochemical adaptation was temporally associated with marked increases in intestinal mucosal ODC activity and putrescine and spermidine content (10). Furthermore, indices of mucosal cell proliferation, including new DNA synthesis, crypt cell proliferation, and crypt cell labeling index, were all highly correlated with the time course of the increase in ODC activity (10).

Although these previous results suggest that the polyamines may be essential in intestinal adaptation, they provide no information on which processes of growth and differentiation

1. Abbreviations used in this paper: CCPR; crypt cell production rate; DFMO, $\alpha$-difluoromethyl ornithine; ODC, ornithine decarboxylase. 
are mediated, or even whether the polyamines are required. If, as in in vitro cell studies, the polyamines are somehow required for these in vivo growth processes, do the polyamines play a role in the onset of new DNA synthesis? These questions are important in deciphering the potential role of polyamines in growth processes in vivo. Therefore, in the present study, we have examined which components of the intestinal mucosal adaptation process are directly dependent upon increased polyamine biosynthesis. We have used the specific irreversible ODC inhibitor, $\alpha$-difluoromethyl ornithine (DFMO, MDL 71,782, Merrell Dow Research Institute, Cincinnati, $\mathrm{OH})$ to suppress the increases in intestinal mucosal ODC activity and to assess the resultant effects on intestinal adaptation. We now report that the increases in polyamine biosynthesis during intestinal adaptation are essential for the increase in mucosal cell DNA synthesis which precedes the crypt cell proliferative activity during postjejunectomy adaptive hyperplasia of the intestinal mucosa in vivo.

\section{Methods}

Animal care. Adult female Wistar-Lewis rats, weighting $180-200 \mathrm{~g}$ (Charles River Breeding Laboratories, Inc., Wilmington, MA) were allowed to acclimate to our animal facilities for $2 \mathrm{wk}$ before all studies. Rats were kept four to a cage and housed with 12-h light (7 a.m.7 p.m.) and 12-h dark cycles, and given regular laboratory rat chow and water ad libitum. The DFMO animals were given DFMO as a $2 \%$ solution in the drinking water $(3.6 \mathrm{~g} / \mathrm{kg}$ per $\mathrm{d})$ beginning $3 \mathrm{~d}$ before surgery.

Surgery and tissue sampling. For jejunectomy, the animals were anesthetized lightly with Ketamine, and underwent $50 \%$ proximal small intestinal resection ( $\sim 5 \mathrm{~cm}$ in length), beginning $5 \mathrm{~cm}$ distal to the ligament of Treitz. The remaining intestine was anastomosed by an end-to-end enteroenterostomy, using interrupted 6-0 silk (10, 11). Sham-operated transection controls underwent jejunal transection $5 \mathrm{~cm}$ distal to the ligament of Treitz, without any intestine removed, followed by reanastomosis $(10,11)$. Daily weights were measured. Animals were then killed at $1,2,3,4,5,7,10$, and $14 \mathrm{~d}$ after surgery, as well as on day 0 just before surgery. A total of 6-10 animals from each experimental group was used at each time point.

$30 \mathrm{~min}$ before killing, each animal was injected intraperitoneally with $0.5 \mathrm{mCi} / \mathrm{kg}$ body weight [methyl- ${ }^{3} \mathrm{H}$ ] thymidine $(5 \mathrm{Ci} / \mathrm{mmol}$, Amersham Corp., Arlington Heights, IL). For studies of the crypt cell production rate (CCPR), each group of four animals was injected with $1 \mathrm{mg} / \mathrm{kg}$ body weight of vincristine sulfate (Sigma Chemical Co., St. Louis, MO) at either $0,30,60,90$, or 120 min before killing.

After killing, the entire small intestine was removed from the peritoneal cavity and the intestinal contents were removed by gentle flushing with iced saline. The length of the intestine was then measured under 25-g tension, and its weight measured. The proximal $10 \mathrm{~cm}$ of ileum, extending from $5 \mathrm{~cm}$ distal to the anastomosis, was termed the "proximal ileum". The postresection adaptive changes in this ileal segment are representative of the adaptive changes in the entire length of the remaining intestine (9-13). The proximal ileum was excised for subsequent studies, taking care to avoid macroscopic Peyer's patches. After resection, this segment was divided into five equal lengths. The most proximal segment was used for histological and autoradiographic studies, the second segment for CCPR studies, the third for scintillation counting, and the fourth and fifth segment for biochemical assays.

Crypt dissection. For crypt dissection, the method of Clarke (15) and Wright et al. (16) were used. Briefly, the intestinal segments were fixed in Carnoy's fixative. After rehydration and hydrolysis in $1 \mathrm{~N}$ hydrochloric acid, the tissue was stained with the Feulgen reaction. A thin section of the stained intestine was then placed on a microscope slide in several drops of acetic acid. The crypts were then individually teased out using fine dissection needles. For determination of disintegrations per crypt (dpm/crypt), 50 crypts were dissected out and placed into liquid scintillation vials, and dissolved in $0.5 \mathrm{ml}$ of Protosol (New England Nuclear, Boston, MA). After solubilization at $37^{\circ} \mathrm{C}$ for $1 \mathrm{~h}$, $7 \mathrm{ml}$ of Aquasol-2 (New England Nuclear) was then added, and the vial placed in a liquid scintillation counter, and the radioactivity measured.

For the CCPR studies, triplicate groups of 10 crypts were dissected out and gently squashed under a microscope coverslip. The total number of cells in each crypt and the total number of arrested metaphases were counted. The CCPR was expressed as the number of arrested metaphases per 1,000 cells/h.

Morphometry. For morphometric measurements, well oriented 10$\mu \mathrm{m}$ paraffin sections, cut parallel to the villus-crypt axis, were stained by hematoxylin and eosin. The mucosal villus height and crypt depth were then measured in well-oriented sections using an ocular micrometer.

Biochemical assays. ODC activities were measured in homogenates of mucosal scrapings by the quantitation of ${ }^{14} \mathrm{CO}_{2}$ that was liberated from the ${ }^{14} \mathrm{C}$-labeled substrate, ornithine, as previously described (10). Briefly, mucosal scrapings were homogenized 1:10 (wt/vol) in $100 \mathrm{mM}$ sodium phosphate buffer, $\mathrm{pH} 7.2$, which contained $5 \mathrm{mM}$ dithiothreitol. The reaction mixture contained $80 \mu$ l of the mucosal homogenate, $0.02 \mu \mathrm{mol}$ of pyridoxal phosphate, and $0.5 \mu \mathrm{Ci}$ of DL- $\left[1-{ }^{14} \mathrm{C}\right]$ ornithine hydrochloride ( $58 \mathrm{mCi} / \mathrm{mmol}$, Amersham Corp.), in a total volume of $0.2 \mathrm{ml}$ of the phosphate-dithiothreitol buffer.

For polyamine analyses, the mucosal homogenate was mixed with equal volumes of $0.4 \mathrm{M}$ perchloric acid and left on ice for $1 \mathrm{~h}$. The homogenate was then centrifuged at $15,000 \mathrm{~g}$ for $15 \mathrm{~min}$ and the supernatant was then filtered through Millipore filters $(0.22 \mu \mathrm{m})$. Aliquots of the filtered acid extract were then analyzed for polyamine concentrations using a Dionex D-300 amino acid analyzer with a Dionex P/N 30831 cation separator column (Dionex Corp., Sunnyvale, CA). Polyamines were eluted using an eluent flow rate of $30 \mathrm{ml} / \mathrm{h}$ and reagent (orthophthaldehyde) flow rate of $18 \mathrm{ml} / \mathrm{h}$. The elution buffers were as follows: for equilibration and putrescine, $0.3 \mathrm{M} \mathrm{Na}$ buffer $(\mathrm{pH}$ 5.8); for spermidine, $0.7 \mathrm{M} \mathrm{Na}$ buffer ( $\mathrm{pH} \mathrm{5.55);} \mathrm{and} \mathrm{for} \mathrm{spermine,} 1.5$ M Na buffer (pH 5.55).

DNA was quantitated fluorometrically after incubation with ethidium bromide (17). Mucosal homogenate was diluted 1:100 with distilled water and transferred to a total volume of $1.45 \mathrm{ml}$ of phosphate-buffered saline, $\mathrm{pH} 7.0$, which contained $0.1 \mathrm{M}$ sodium chloride, $0.05 \mathrm{M}$ sodium phosphate, $0.2 \mathrm{mM}$ EDTA, $0.15 \mathrm{mg}$ pronase, and $75 \mu \mathrm{g}$ of RNase A. The mixture was incubated at $37^{\circ} \mathrm{C}$ for 30 min. $3.75 \mu \mathrm{g}$ ethidium bromide in a volume of $50 \mu \mathrm{l}$ was then added and the fluorescence of an aliquot of the resultant mixture was determined using an excitation wavelength of $360 \mathrm{~nm}$ and an emission wavelength of $590 \mathrm{~nm}$. All reagents used were reagent grade and were obtained from Sigma Chemical Co.

Statistical analysis. CCPR was calculated by first plotting the 
number of arrested metaphases against the time after vincristine administration, and then fitting a line by linear regression. Data were analyzed using $t$ test and the Wilcoxon rank sum method at the $P$ $<0.05$ level of significance (18).

\section{Results}

Weight gain and oral intake. After the intestinal surgery, all rats lost 3-4\% of their body weight. The surgical mortality was $5 \%$, which is comparable with other studies $(11-13)$. The rate at which the control jejunectomy animals gained weight was also comparable with previous studies (10-13). The DFMO animals had a slightly slower rate of weight gain post jejunectomy, but the difference was not statistically significant $(P$ $=0.68$; Fig. 1).

Cellular events in mucosal adaptation. Mucosal ODC activity in the normal adult rat intestine is normally very low (Fig. 2, day 0). After jejunectomy in the control animals, there is a marked increase in mucosal ODC activity, with the maximal increase occurring on day 2. Mucosal ODC activity increased by 44 -fold in the jejunectomy controls, and decreased rapidly by day 7 , and returned towards normal by day 14 (Fig. 2). Concurrent with the increase in mucosal ODC activity, mucosal polyamine content also increased. Mucosal putrescine was $387 \%$, spermidine $233 \%$, and spermine $135 \%$ of their respective prejejunectomy levels (Table I). The sham-operated transection controls showed no appreciable mucosal adaptation, which was similar to previous studies $(10,11)$. The data for the transection controls stayed essentially at day 0 levels, and are thus not shown in the figures, for the sake of clarity.

Mucosal DNA content was used as an estimation of the total mucosal enterocyte mass (12). Mucosal DNA content in jejunectomy controls increased by $67 \%$ over preresection levels, with most increases occurring the first $4 \mathrm{~d}$. The DNA specific activity (amount of thymidine radioactivity in DNA, expressed in terms of total DNA present) was used as an estimation of the proportion of proliferating cells (12). Increased DNA specific activity after injection of $\left[{ }^{3} \mathrm{H}\right]$ thymidine was found beginning $1 \mathrm{~d}$ after resection (Fig. 3). The increase in new mucosal DNA synthesis was maximal on day 3 , when the

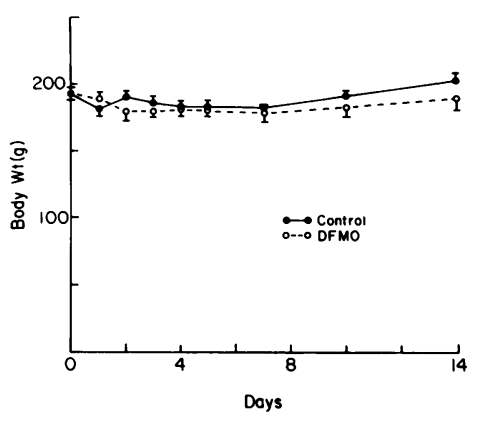

Figure 1. Effect of DFMO on body weights of rats after jejunectomy. Animals underwent $50 \%$ proximal intestinal resection, and then were either given water $(\bullet)$ or $3.6 \mathrm{~g} / \mathrm{kg}$ per d DFMO in the drinking water (o). Results are means \pm SEM from 6 to 10 animals. There was no statistically significant difference between the two groups $(P=0.68)$.

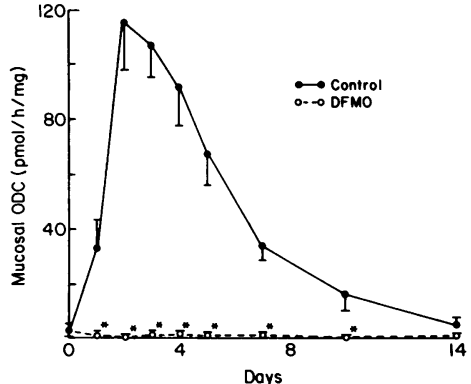

Figure 2. Effect of DFMO on the increase in mucosal ODC activity after jejunectomy. Animals underwent $50 \%$ proximal intestinal resection, and then were given water (๑) or $3.6 \mathrm{~g} / \mathrm{kg}$ per d DFMO (o). ODC activity was measured by ${ }^{14} \mathrm{CO}_{2}$ released from $\left[{ }^{14} \mathrm{C}\right]$ ornithine after incubation with mucosal homogenates. Results are expressed as picomoles of ${ }^{14} \mathrm{CO}_{2}$ released per hour per milligram cell protein, and represent the means \pm SEM from 6 to 10 animals. *, Statistically significant difference from control, $P$ $<0.05$.

amount of radioactivity was increased by $144 \%$ over prejejunectomy levels (Fig. 3).

The uptake of $\left[{ }^{3} \mathrm{H}\right]$ thymidine per crypt $(\mathrm{dpm} / \mathrm{crypt})$ was used as an estimate of the number of crypt cells undergoing DNA synthesis (13). The dpm/crypt in the jejunectomy controls was markedly increased over prejejunectomy levels by day 1 , and was maximal on day 2 (Table II).

The CCPR was considered a direct measurement of the rate of crypt cell production, assuming that each metaphase results in one new mucosal cell, which then migrates up the villus (16). The CCPR in the jejunectomy controls was increased

Table I. Effect of DFMO on Mucosal Polyamine Content after Jejunectomy

\begin{tabular}{llll}
\hline & \multicolumn{3}{l}{$n$ mol/mg cell protein } \\
\cline { 2 - 4 } & Putrescine & Spermidine & Spermine \\
\hline $\begin{array}{l}\text { Jejunectomy control } \\
\text { Day 0 }\end{array}$ & 1.83 & 12.3 & \\
Day 2 & 7.08 & 28.6 & 11.4 \\
Day 7 & 2.53 & 15.7 & 15.4 \\
DFMO & & & 12.8 \\
Day 0 & 1.81 & 11.9 & \\
Day 2 & $2.15^{*}$ & $14.9^{*}$ & 11.7 \\
Day 7 & 1.79 & 11.5 & $12.8^{*}$ \\
\hline
\end{tabular}

Segments of proximal ileum were obtained from rats which underwent jejunectomy. The DFMO animals were given DFMO $3.6 \mathrm{~g} / \mathrm{kg}$ per $d$ in the drinking water. Polyamine content was assayed in perchloric acid extracts of mucosal homogenate fluorometrically on a peptide analyzer. Results are means from 6 to 10 animals. The results on days $1,3,4,5,10$, and 14 show a time course similar to that of mucosal ODC activity in Fig. 2, thus only the results for day 0 , peak on day 2, and return to normal on day 7 are shown. * Statistically significant difference from control, $P<0.05$. 


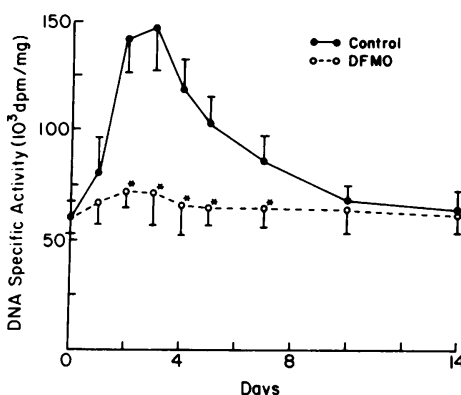

Figure 3. Effect of DFMO on the increase in mucosal DNA specific activity after jejunectomy. Animals underwent $50 \%$ proximal intestinal resection, and then were given water $(\bullet)$ or 3.6 g/kg per d DFMO (o). Animals were also given 0.5 $\mathrm{mCi} / \mathrm{kg}$ body weight $\left[{ }^{3} \mathrm{H}\right]$ thymidine $1 \mathrm{~h}$ before killing. Mucosal DNA con-

tent was assayed fluorometrically after incubation with ethidium bromide. Results are expressed as $10^{3} \mathrm{dpm} / \mathrm{mg}$ DNA, and represent the means \pm SEM from 6 to 10 animals. *, Statistically significant difference from control, $P<0.05$.

by day 1 , and was maximal on day 2 , reaching a value of $74.6: 1,000$ cells/ $h$, and represented a $132 \%$ over prejejunectomy levels (Table II).

Table II. Effect of DFMO on Mucosal DNA Content, Thymidine Incorporation, and CCPR

\begin{tabular}{llll}
\hline & $\begin{array}{l}\text { DNA } \\
\text { content }\end{array}$ & $\begin{array}{l}\text { Thymidine } \\
\text { incorporation }\end{array}$ & $\begin{array}{l}\text { CCPR No./1,000 } \\
\text { cells/h }\end{array}$ \\
\hline & $8 / c m$ & $d p m / c r y p t$ & \\
Jejunectomy control & & & \\
Day 0 & 316 & 14.7 & 32.1 \\
Day 2 & 464 & 32.3 & 74.6 \\
Day 7 & 519 & 19.6 & 45.1 \\
DFMO & & & \\
Day 0 & 311 & 14.9 & 31.8 \\
Day 2 & $336^{*}$ & $16.5^{*}$ & $31.0^{*}$ \\
Day 7 & $346^{*}$ & $14.8^{*}$ & $32.9^{*}$ \\
\end{tabular}

Segments of proximal ileum were obtained from rats which underwent jejunectomy. The DFMO animals were given $3.6 \mathrm{~g} / \mathrm{kg}$ per $\mathrm{d}$ DFMO in the drinking water. Animals were also given $0.5 \mathrm{mCi} / \mathrm{kg}$ body weight $\left[{ }^{3} \mathrm{H}\right]$ thymidine $1 \mathrm{~h}$ before killing for thymidine incorporation studies, and $1 \mathrm{mg} / \mathrm{kg}$ vincristine from 30 to $120 \mathrm{~min}$ before killing for CCPR studies. DNA content was quantitated fluorometrically after incubation with ethidium bromide. Crypts were dissected out, the amount of radioactivity in $\mathbf{5 0}$ crypts was measured for thymidine incorporation studies, and the number of arrested metaphases were counted for CCPR studies. Results are means from 6 to 10 animals for DNA content and thymidine incorporation studies and means from 6 separate determinations from four animals at each time point for CCPR studies. The time course of the results on days $1,3,4,5,10$, and 14 is similar to that for DNA specific activity for Fig. 3, and thus only the results for day 0 , peak on day 2 , and return to normal on day 7 are shown.

* Statistically significant difference from control, $P<0.05$.

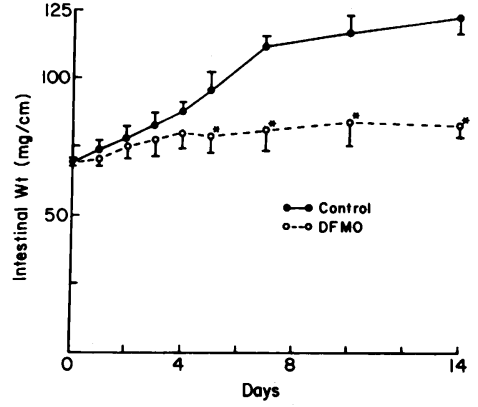

Figure 4. Effect of DFMO on adaptive intestinal weight gain after jejunectomy. Animals underwent $50 \%$ proximal intestinal resection and then were given water (०) or $3.6 \mathrm{~g} / \mathrm{kg}$ per d DFMO (o). Segments of proximal ileum were obtained at killing. Segment length was measured under $25 \mathrm{~g}$ tension and segment

wet weight was obtained. Results are means \pm SEM from 6 to 10 animals. *, Statistically significant difference from control, $P<0.05$.

The weight of the proximal ileum in the jejunectomy controls increased by $77 \%$ over prejejunectomy levels, with most of the increase occurring over the first $7 \mathrm{~d}$ (Fig. 4). Mucosal height also increased in the jejuniectomy controls. The increases in mucosal height were maximal over the first $7 \mathrm{~d}$. Villus height increased by $57 \%$ and crypt depth increased by $68 \%$ (Fig. 5 ).

The sequence of events that leads to adaptive mucosal hyperplasia in vivo might be depicted schematically as in Fig. 6. Within $24 \mathrm{~h}$ after the stimulus of jejunectomy, mucosal ODC activity increases and mucosal polyamine levels rise. This is closely followed, within another $24 \mathrm{~h}$, by an increase in DNA synthesis, which is followed in another $12 \mathrm{~h}$ by increased crypt cell proliferation. Subsequently, after another

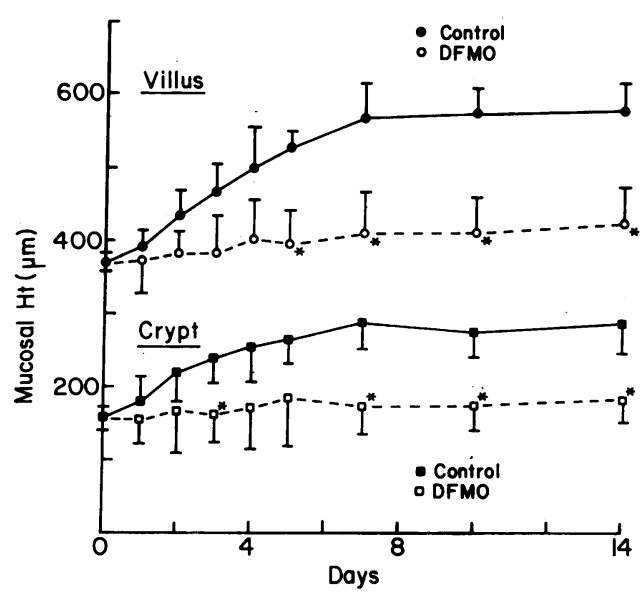

Figure 5. Effect of DFMO on the adaptive increase in mucosal height after jejunectomy. Animals underwent $50 \%$ proximal intestinal resection and then were given water $(\bullet)$ or $3.6 \mathrm{~g} / \mathrm{kg}$ per d DFMO (o). Segments of proximal ileum were fixed for paraffin sections. Welloriented $10-\mu \mathrm{m}$ sections were stained with hematoxylin and eosin, and mucosal villus and crypt height were measured using an ocular micrometer. Results are means \pm SEM from 6 to 10 animals. *, Statistically significant difference fróm control, $P<0.05$. 


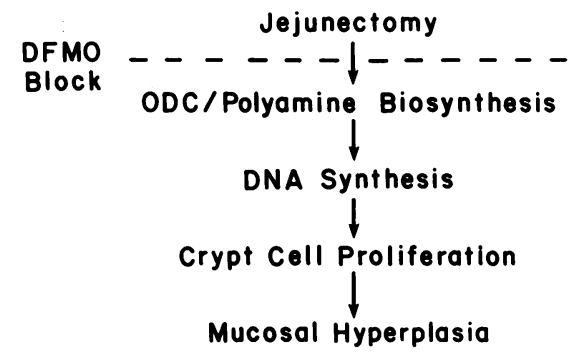

Figure 6. Schema of the sequence of cellular events leading to mucosal adaptation after jejunectomy. The data for control animals from the present and previous studies $(9,10)$ are summarized and depicted schematically. The schematic for the sequence of cellular events thus indicates when each parameter depicted is substantially increased from basal, control levels. ODC/polyamine biosynthesis represents the increase in ODC activity and polyamine content, DNA synthesis the increase in DNA content and DNA specific activity, crypt cell proliferation the increase in CCPR, and mucosal hyperplasia the increase in mucosal height and weight. The dotted line for DFMO block depicts the suppression by DFMO of all cellular events leading to mucosal adaptation.

$48 \mathrm{~h}$, this results in mucosal hyperplasia, as evidenced by increased mucosal height and weight. Thus, an orderly sequence of biochemical events follows the stimulus of jejunectomy and results in mucosal hyperplasia.

DFMO suppression of DNA synthesis. Crypt cell proliferation and mucosal hyperplasia. The effect of DFMO in the complete suppression of the cellular events leading to mucosal hyperplasia and in abolition of the ultimate hyperplasia can be clearly seen in Figs. 2-6. These effects are especially remarkable when one considers the lack of major systemic toxicity, such as marked weight loss or the lack of specific toxicity to the intestinal mucosa, evidenced by a lack of diarrhea.

DFMO suppressed mucosal ODC activity by $99.7 \%$ (Fig. 2). The increases in mucosal putrescine, spermidine, and spermine content were also suppressed by 94,84 , and $40 \%$, respectively (Table I). This clearly documents DFMO to be an effective inhibitor of ODC activity and polyamine biosynthesis in the intestinal mucosa in vivo.

DFMO in vivo also suppressed mucosal DNA synthesis. This was evidenced by the $>87 \%$ suppression of the increases in DNA-specific activity (Fig. 3) and in mucosal DNA content and thymidine incorporation into mucosal DNA (Table II). This was followed by suppression in crypt cell proliferation, as shown by the virtually $100 \%$ inhibition of the increase in CCPR (Table II).

This DFMO suppression of mucosal ODC activity, polyamine biosynthesis, followed by inhibition of mucosal DNA synthesis and crypt cell proliferation, resulted in the abolition of mucosal hyperplasia. The increase in mucosal weight was suppressed by $75 \%$ (Fig. 4), and the increases in mucosal villus height and crypt depth by 74 and $81 \%$, respectively (Fig. 5).

\section{Discussion}

Increased ODC activity and polyamine biosynthesis are characteristically associated with the rapid growth of cells and tissues (1-8). However, it has been difficult to clearly document the exact functional role of the increases in ODC activity, especially in the intact animal. We have used the rapidly proliferating intestinal mucosa as a model for studying the role of polyamine biosynthesis in cell proliferation in vivo because $(a)$ several well-documented processes of stimulated mucosal cell proliferation are known, $(b)$ the mucosa can be manipulated locally through pharmacologic and/or hormonal maneuvers, and $(c)$ mucosal cell populations can be readily obtained during key points in these growth processes.

The specific inhibitor of ODC, DFMO (MDL 71,782, Merrell Dow Research Institute), has made possible the sustained depletion of polyamines and allows documentation of the critical role of the polyamines in several biological processes $(5,19-21)$.

This drug is a specific, enzyme-activated, irreversible, suicide inhibitor of ODC, and has no other known pharmacologic effect (22). Its antiproliferative effect has been shown to be unaccompanied by toxic effects, and has been reversible by the addition of exogenous biosynthetic products, polyamines, in in vitro studies $(5,21)$. Furthermore, we have previously shown that normal adult rats, given DFMO for 2 wk in amounts similar to the present study, showed no histologic or biochemical changes in the intestinal mucosa, except for the suppression of basal levels of ODC activity (23). Thus, the inhibition of intestinal adaptation by DFMO demonstrated in the current study can be attributed to the suppression of ODC activity and subsequent polyamine biosynthesis.

Our current studies using DFMO in intestinal adaptation after jejunectomy clearly document the critical role of polyamine biosynthesis in the onset of intestinal mucosal cell proliferation. Inhibition of the increase in ODC activity and polyamine biosynthesis resulted in the abolition of new mucosal DNA synthesis and intestinal adaptation. We have outlined the sequential nature of the cellular events measured, and the inhibition by DFMO of the entire sequence, leading ultimately to abolition of mucosal hyperplasia (Fig. 6). The data show that in vivo, the increases in ODC activity and polyamine biosynthesis are essential for intestinal mucosal growth processes and that they mediate these growth processes through allowing the increased DNA synthesis which precede cell proliferation.

The specific results from our present study of intestinal adaptation have general implications for the processes of DNA synthesis and cell replication in the intestinal mucosa. We have also previously shown that mucosal ODC activity and polyamine content increased during intestinal maturation in newborn rats, during recovery of intestinal mucosa after cytotoxic injury in the adult rat (23), and during lactationassociated intestinal adaptation (24). In each of these situations, the increase in ODC activity occurs in the early stages of the 
intestinal mucosal response and probably, as in the present study, before DNA synthesis and cell proliferation. We have thus shown that increased mucosal ODC activity and increased polyamine content may be common events that precede DNA synthesis and cell proliferation in all four models of intestinal functional adaptive responses that have been studied to date.

The present results also further emphasize the functional role of the polyamine biosynthesis pathway in DNA synthesis and cell proliferation in general, and are similar to our previous findings in promyelocytic leukemic cells. In the process of postresectional intestinal adaptation, our previous and current data on crypt cell production rate and new DNA synthesis document that the adaptive response is accomplished mainly by the proliferation of a new population of cells in the crypt, as opposed to accelerated maturation of the existing villus cells $(10,24)$. Polyamine biosynthesis would appear to play a much more important role in this initial proliferation of the crypt cell, than in the subsequent differentiation of the intestinal mucosal cell thus produced. This is consistent with our previous results in the chemically induced differentiation of the cultured human progranulocytic leukemia cell, HL-60, in which we showed that transient increases in ODC activity were associated with the onset of both proliferation and differentiation of the HL-60 cell, but appear to be important functionally only for the proliferation and not for the differentiation process (25).

In summary, our results document that, during postresectional adaptive hyperplasia of the intestinal mucosa, the increases in ornithine decarboxylase activity and subsequent polyamine biosynthesis are critical and necessary for the increases in proliferative activity of the intestinal crypt cell compartment, and that the critical step mediated by the polyamines in this adaptive growth process is the onset of new DNA synthesis. These findings in vivo emphasize the need for studying, in much further detail, the nature of the molecular interactions between polyamines, the mechanics of cell proliferation, and specific steps in DNA synthesis as well as potential interactions with other mediators of intestinal epithelial proliferation, such as epidermal growth factor (26), and the prostaglandins (27). Our data also provide further "biologic" significance to the study of interactions of polyamines with the DNA molecule.

\section{Acknowledgments}

We thank Drs. Elliot Weser and R. Hermon Dowling for initially suggesting the interesting models of intestinal adaptation, and especially Dr. Weser for continued technical advice, support, and assistance. We thank Dr. John Hilton for assistance with polyamine analyses, and Dr. Nicholas A. Wright for helpful discussions on the CCPR technique. We also thank Drs. Albert H. Owens, Jr. and Thomas R. Hendrix for advice, encouragement, and support, and Jeffrey A. Smith and Ann C. Vandeventer for technical assistance.

This work was supported in part by a gift from the W. W. Smith Fund, and grant AM27447 from the National Institutes of Health.

\section{References}

1. Tabor, C. W., and H. Tabor. 1984. Polyamines. Annu. Rev. Biochem. 53:749-790.

2. Williams-Ashman, H. G., and Z. N. Canellakis. 1979. Polyamines in mammalian biology and medicine. Perspect. Biol. Med. 22:421453.

3. Janne, J., H. Poso, and A. Raina. 1978. Polyamines in rapid growth and cancer. Biochim. Biophys. Acta. 473:241-293.

4. Russell, D. H., and B. G. M. Durie. 1978. Polyamines as Biochemical Markers of Normal and Neoplastic Growth. Raven Press, New York

5. Pegg, A. E., and P. P. McCann. 1982. Polyamine metabolism and function. Am. J. Physiol. 243:C212-C221.

6. McCann, P. P. 1980. Regulation of ornithine decarboxylase in eukaryotes. In Polyamines in Biomedical Research. J. M. Gaugas, editor. John Wiley \& Sons, New York. 109-123.

7. Lembach, K. J. 1974. Regulation of growth in vitro. 1. Control of ornithine decarboxylase levels in untransformed mouse fibroblasts by serum. Biochim. Biophys. Acta 354:88-100.

8. Oka, T., and J. W. Perry. 1976. Studies on regulatory factors of ornithine decarboxylase activity during development of mouse mammary epithelium in vitro. J. Biol. Chem. 251:1738-1744.

9. Luk, G. D., and S. B. Baylin. 1982. Ornithine decarboxylase in intestinal maturation and adaptation. In Mechanisms of Intestinal Adaptation. J. W. L. Robinson, R. H. Dowling, and E. O. Reicken, editors. MTP Press, Ltd., Lancaster, England. 65-80.

10. Luk, G. D., and S. B. Baylin. 1983. Polyamines and intestinal growth-increased polyamine biosynthesis after jejunectomy. Am. J. Physiol. 245:G656-G660.

11. Weser, E., and M. H. Hernandez. 1971. Studies of small bowel adaptation after intestinal resection in the rat. Gastroenterology. 60:6975.

12. Obertop, H., S. Nundy, D. Malamud, and R. A. Malt. 1977. Onset of cell proliferation in the shortened gut: rapid hyperplasia after jejunal resection. Gastroenterology. 72:267-270.

13. Hanson, W. R., J. W. Osborne, and J. G. Sharp. 1977. Compensation by the residual intestine after intestinal resection in the rat. 1. Influence of amount of tissue removed. Gastroenterology. 72:692-700.

14. Williamson, R. C. N. 1978. Intestinal adaptation. N. Engl. J. Med. 298:1393-1402, 1444-1450.

15. Clarke, R. M. 1971. A comparison of metaphase arresting agents and tritiated thymidine in measurement of the rate of entry into mitosis in the crypts of Lieberkuhn of the rat. Cell Tissue Kinet. 4:263-272.

16. Wright, N. A., and D. R. Appleton. 1980. The metaphase arrest technique. A critical review. Cell Tissue Kinet. 13:643-663.

17. Boer, G. J. 1975. A simplified microassay of DNA and RNA using ethidium bromide. Anal. Biochem. 65:225-231.

18. Armitage, P. 1971. Statistical Methods in Medical Research. Blackwell Scientific Publications, Oxford, England.

19. Seiler, N., C. Danzin, J. Prakash, and J. Koch-Weser. 1978. Effects of ornithine decarboxylase inhibitors in vivo. In Enzyme Activated Irreversible Inhibitors. N. Seiler, M. J. Jung, and J. KochWeser, editors. Elsevier/North Holland, New York. 55-71.

20. Sjoerdsma, A. 1981. Suicide enzyme inhibitors as potential drugs. Clin. Pharmacol. Ther. 30:3-22. 
21. Mamont, P. S., M. C. Duchesne, A. M. Joder-Ohlenbusch, and J. Grove. 1978. Effects of ornithine decarboxylase inhibitors on cultured cells. In Enzyme Activated Irreversible Inhibitors. N. Seiler, M. J. Jung, and J. Koch-Weser, editors. Elsevier/North Holland, New York. 43-54.

22. Metcalf, B. W., P. Bey, C. Danzin, M. J. Jung, P. Casara, and J. P. Vevert. 1978. Catalytic irreversible inhibition of mammalian ornithine decarboxylase (E.C. 4.1.1.17) by substrate and product analogues. J. Am. Chem. Soc. 110:2551-2553.

23. Luk, G. D., L. J. Marton, and S. B. Baylin. 1980. Ornithine decarboxylase is important in intestinal mucosal maturation and recovery from injury in rats. Science (Wash. D.C.). 210:195-198.

24. Yang, P., G. D. Luk, and S. B. Baylin. 1982. Ornithine decarboxylase plays a critical role in intestinal adaptation during lactation. Gastroenterology 82:1215. (Abstr.)

25. Luk, G. D., C. I. Civin, R. M. Weissman, and S. B. Baylin. 1982. Ornithine decarboxylase: essential in proliferation but not differentiation of human promyelocytic leukemia cells. Science (Wash. D.C.). 216:75-77.

26. Feldman, E. J., D. Aures, and M. I. Grossman. 1978. Epidermal growth factor stimulates ornithine decarboxylase activity in the digestive tract of mouse. Proc. Soc. Exp. Biol. Med. 159:400-402.

27. Craven, P. A., R. Saito, and F. R. DeRubertis. 1983. Role of local prostaglandin synthesis in the modulation of proliferative activity of rat colonic synthesis in the modulation of proliferative activity of rat colonic epithelium. J. Clin. Invest. 72:1365-1375. 